\title{
Contribution of the Microfractography on the Study of Mechanical Properties of
} Alloys.

\author{
Carlos Lariot $^{1 *}$, Amalek Orellana ${ }^{1}$, Xenia Suárez ${ }^{2}$ \\ 1- Institute of Science and Technology of Materials (IMRE-UH) Havana, Cuba \\ 2- Laboratory of Tropicalization Assays (LABET) Havana, Cuba \\ *lariot@imre.uh.cu
}

The fracture tenacity of a material depends on its ability to deform plastically and absorb energy during the fracture process.

The Scanning Electron Microscope (SEM) with its 3D appearance images and great depth of focus allows the best microscopic characterization of the fissure propagation process that provides valuable information about the structure of the alloy and its mechanical properties.

In the AA3003 aluminum alloy the effect of the deformation on the structure and its mechanical properties is very marked. The metallography clarified the influence of the phase transformations occurred [1], but only the fractography at high magnification allowed a very graphic visual characterization of mechanical properties.

The Al-Si alloy are prone to pitting corrosion in the presence of the chloride ion. The accelerated corrosion tests allowed to diagnose the effect of this type of corrosion on the mechanical properties of the A6060 alloy, but it was the fractography that clarified key aspects of the corrosion mechanism [2].

The VEGA 3 (SEM) of TESCAN was used coupled to an INCA spectrometer Model 0007 (EDSX) of Oxford.

The fractographic analysis of AA3003 alloy showed the decisive influence of the precipitates in the fracture. The prevalence shown by the domes of ductile rupture in the state of delivery of the alloys and laminated is consistent with the result of the mechanical tests of the alloy in those states.

The increase of the exposure time to corrosion in $\mathrm{Al}-\mathrm{Mg}-\mathrm{Si}$ alloys does not influence the hardness or mechanical strength of the alloy, but it does increase the plastic deformation. The fractography of the tensile specimens showed consistent results with the mechanical tests, clarifying the role of defects and inclusions on the action of the corrosion. 


\section{References:}

[1]- Orellana A. Tesis Maestría. Universidad de La Habana, 2014.

[2]- Xenia Suárez, Lisbet Acosta, Francisco Corvo, Carlos Lariot. MEMORIAS de Convención

Internacional CUBA INDUSTRIA. Taller Tropicalización. ISBN 978- 959-282-097-5, 3770-3777, 2014

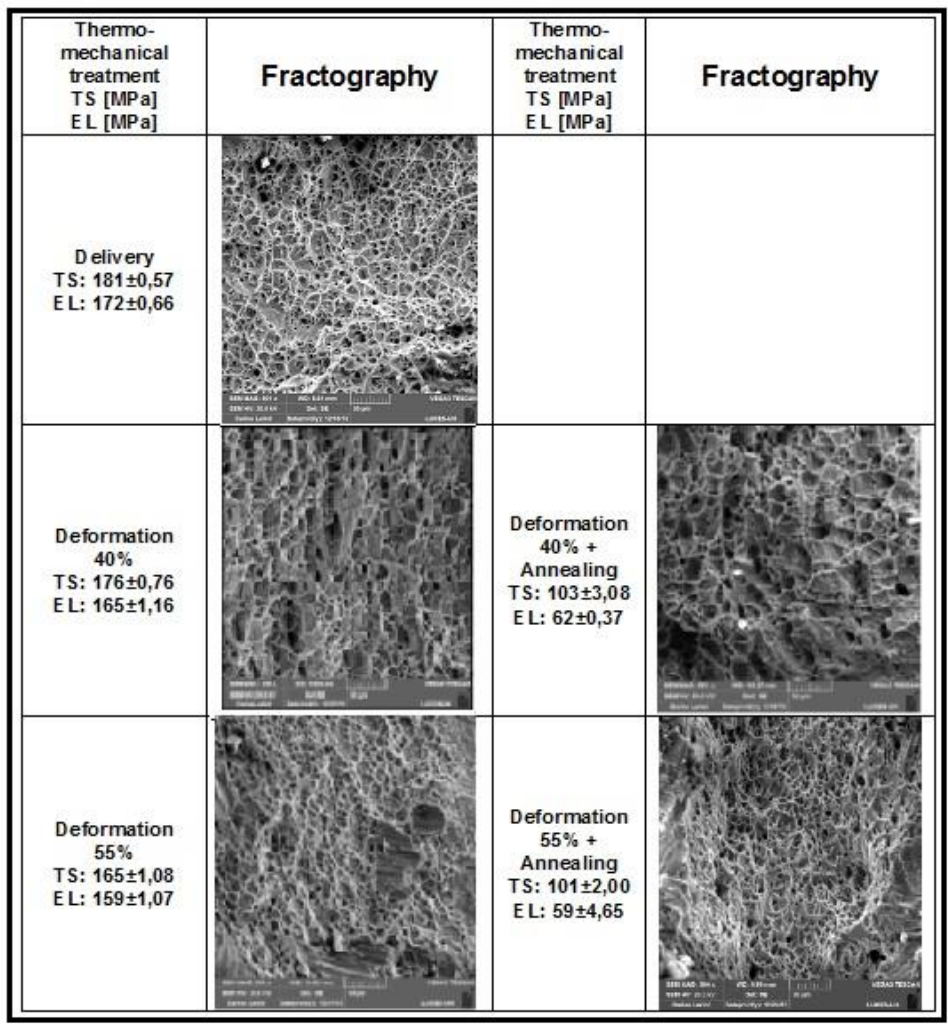

Fig. 1: Micrographs of the fracture surfaces of tensile specimens of the AA3003 alloy in the state of delivery, lamination and annealing. Tensile Strengths (TS) and Elastic Limits (EL) are also shown.

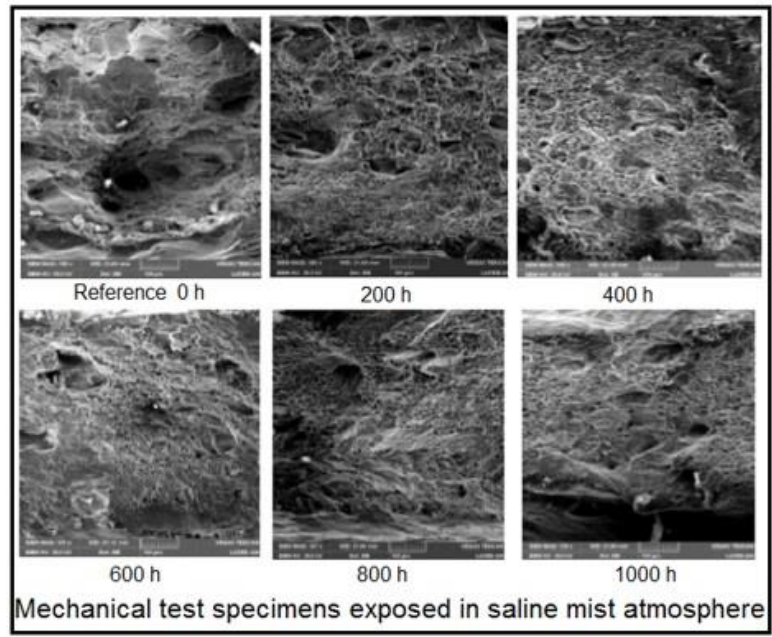

Fig. 2: Micrographs of the fracture surfaces of tensile samples of the A6060 alloy in the state of delivery and exposed in saline mist atmosphere 